\title{
(18)FDG-PET-CT in the follow-up of non-small cell lung cancer patients after radical radiotherapy with or without chemotherapy: An economic evaluation
}

Citation for published version (APA):

van Loon, J., Grutters, J. P. C., Wanders, R., Boersma, L., Dingemans, A-M. C., Bootsma, G., Geraedts, W., Pitz, C., Simons, J. P., Brans, B., Snoep, G., Hochstenbag, M., Lambin, P., \& De Ruysscher, D. (2010). (18)FDG-PET-CT in the follow-up of non-small cell lung cancer patients after radical radiotherapy with or without chemotherapy: An economic evaluation. European Journal of Cancer, 46(1), 110-119. https://doi.org/10.1016/j.ejca.2009.10.028

Document status and date:

Published: 01/01/2010

DOI:

10.1016/j.ejca.2009.10.028

Document Version:

Publisher's PDF, also known as Version of record

Document license:

Taverne

Please check the document version of this publication:

- A submitted manuscript is the version of the article upon submission and before peer-review. There can be important differences between the submitted version and the official published version of record.

People interested in the research are advised to contact the author for the final version of the publication, or visit the DOI to the publisher's website.

- The final author version and the galley proof are versions of the publication after peer review.

- The final published version features the final layout of the paper including the volume, issue and page numbers.

Link to publication

\footnotetext{
General rights rights.

- You may freely distribute the URL identifying the publication in the public portal. please follow below link for the End User Agreement:

www.umlib.nl/taverne-license

Take down policy

If you believe that this document breaches copyright please contact us at:

repository@maastrichtuniversity.nl

providing details and we will investigate your claim.
}

Copyright and moral rights for the publications made accessible in the public portal are retained by the authors and/or other copyright owners and it is a condition of accessing publications that users recognise and abide by the legal requirements associated with these

- Users may download and print one copy of any publication from the public portal for the purpose of private study or research.

- You may not further distribute the material or use it for any profit-making activity or commercial gain

If the publication is distributed under the terms of Article $25 \mathrm{fa}$ of the Dutch Copyright Act, indicated by the "Taverne" license above, 


\title{
${ }^{18}$ FDG-PET-CT in the follow-up of non-small cell lung cancer patients after radical radiotherapy with or without chemotherapy: An economic evaluation
}

\author{
Judith van Loon ${ }^{a, *}$, Janneke P.C. Grutters ${ }^{a, i}$, Rinus Wanders ${ }^{a}$, Liesbeth Boersma ${ }^{a}$, \\ Anne-Marie C. Dingemans ${ }^{d}$, Gerben Bootsma ${ }^{e}$, Wiel Geraedts ${ }^{f}$, Cordula Pitz ${ }^{g}$, \\ Jean Simons ${ }^{h}$, Boudewijn Brans ${ }^{b}$, Gabriel Snoep ${ }^{c}$, Monique Hochstenbag ${ }^{d}$, \\ Philippe Lambin ${ }^{a}$, Dirk De Ruysscher ${ }^{a}$ \\ ${ }^{a}$ Department of Radiation Oncology (Maastro Clinic), GROW Research Institute, Maastricht University Medical Centre ${ }^{+}$, \\ Maastricht, The Netherlands \\ ${ }^{\mathrm{b}}$ Department of Nuclear Medicine, Maastricht University Medical Centre ${ }^{+}$, Maastricht, The Netherlands \\ ${ }^{c}$ Department of Radiology, Maastricht University Medical Centre ${ }^{+}$, Maastricht, The Netherlands \\ ${ }^{\mathrm{d}}$ Department of Pulmonology, Maastricht University Medical Centre ${ }^{+}$, Maastricht, The Netherlands \\ e Department of Pulmonology, Atrium Medical Centre, Heerlen, The Netherlands \\ ${ }^{\mathrm{f}}$ Department of Pulmonology, Orbis Medical Centre, Sittard, The Netherlands \\ g Department of Pulmonology, Laurentius Hospital, Roermond, The Netherlands \\ h Department of Pulmonology, St. Jans Hospital, Weert, The Netherlands \\ ${ }^{\mathrm{i}}$ Department of Health Organization, Policy and Economics, CAPHRI Research Institute, Maastricht University Medical Centre ${ }^{+}$, \\ Maastricht, The Netherlands
}

\section{A R T I C L E I N F O}

Article history:

Received 12 October 2009

Accepted 29 October 2009

Available online 26 November 2009

Keywords:

Cost-effectiveness

Follow-up

Non-small cell lung cancer

PET

\begin{abstract}
A B S T R A C T
Background: The optimal follow-up strategy of non-small cell lung cancer (NSCLC) patients after curative intent therapy is still not established. In a recent prospective study with 100 patients, we showed that a FDG-PET-CT 3 months after radiotherapy (RT) could identify progression amenable for curative treatment in $2 \%$ (95\% confidence interval (CI): $1-7 \%$ ) of patients, who were all asymptomatic. Here, we report on the economic evaluation of this study.

Patients and methods: A decision-analytic Markov model was developed in which the longterm cost-effectiveness of 3 follow-up strategies was modelled with different imaging methods 3 months after therapy: a PET-CT scan; a chest CT scan; and conventional follow-up with a chest X-ray. A probabilistic sensitivity analysis was performed to account for uncertainty. Because the results of the prospective study indicated that the advantage seems to be confined to asymptomatic patients, we additionally examined a strategy where a PET-CT was applied only in the subgroup of asymptomatic patients. Cost-effectiveness of the different follow-up strategies was expressed in incremental cost-effectiveness ratios (ICERs), calculating the incremental costs per quality adjusted life year (QALY) gained. Results: Both PET-CT- and CT-based follow-up were more costly but also more effective than conventional follow-up. CT-based follow-up was only slightly more effective than conventional follow-up, resulting in an incremental cost-effectiveness ratio (ICER) of
\end{abstract}

\footnotetext{
* Corresponding author: Address: MAASTRO Clinic, Dr. Tanslaan 12, NL-6229 ET Maastricht, The Netherlands. Tel.: +31 88 4455666; fax: +31884455667.

E-mail address: Judith.vanloon@maastro.nl (J. van Loon).

0959-8049/\$ - see front matter @ 2009 Elsevier Ltd. All rights reserved.

doi:10.1016/j.ejca.2009.10.028
} 
$€ 264.033$ per QALY gained. For PET-CT-based follow-up, the ICER was $€ 69.086$ per QALY gained compared to conventional follow-up. The strategy in which a PET-CT was only performed in the asymptomatic subgroup resulted in an ICER of $€ 42.265$ per QALY gained as opposed to conventional follow-up. With this strategy, given a ceiling ratio of $€ 80.000$, PETCT-based follow-up had the highest probability of being cost-effective (73\%).

Conclusions: This economic evaluation shows that a PET-CT scan 3 months after (chemo)radiotherapy with curative intent is a potentially cost-effective follow-up method, and is more cost-effective than CT alone. Applying a PET-CT scan only in asymptomatic patients is probably as effective and more cost-effective. It is worthwhile to perform additional research to reduce uncertainty regarding the decision concerning imaging in the follow-up of NSCLC.

(c) 2009 Elsevier Ltd. All rights reserved.

\section{Introduction}

The most effective follow-up strategy for non-small cell lung cancer (NSCLC) patients treated with curative intent with radiotherapy (RT) with or without chemotherapy is still not established. This uncertainty is reflected in the large heterogeneity in recommendations from the different cancer societies, diverging from no imaging at all to repeated imaging with chest CT scans. ${ }^{1}$ The added value of chest X-rays and/or chest CT has not been confirmed in any prospective study. A major reason for this lack of efficacy is the poor discriminating capacity of both imaging modalities. Here, ${ }^{18}$ FDG-PET-CT could have additional benefit, which has shown to be more accurate than CT in the evaluation of response to treatment as well as in outcome prediction. ${ }^{2-4}$ We recently reported the results of a prospective study in 100 patients treated with chemo-RT or RT alone with curative intent, which showed that indeed, an FDG-PET-CT 3 months after therapy can detect progression amenable for treatment with curative intent, and hereby, possibly lead to an increase in survival. ${ }^{5}$ Progressive disease (PD) amenable for curative treatment, however, was only found in
$2 \%$ (95\% confidence interval (CI): $1-7 \%$ ) of patients. The study showed that the advantage seemed to be confined to the patient group that did not have symptoms at the time that the PET-CT scan was performed. In this patient group, 5\% $(95 \%$ CI: $2-15 \%$ ) had progression, potentially amenable for curative therapy, which were all detected with FDG-PET, not with CT alone. In contrast, none of the symptomatic patients were diagnosed with progression with curative treatment options.

While a PET-CT scan 3 months post-treatment thus seems to be potentially beneficial, at least in a subset of patients, it is also more costly. This raises the question regarding the costeffectiveness of a PET-CT-based follow-up method compared to usual follow-up with either repeated chest X-rays or CT scans, or imaging on the basis of symptoms. In order to make an evidence-based decision regarding which follow-up strategy to prefer, the costs of each strategy are essential to take into account. Information regarding cost-effectiveness can be obtained through an economic evaluation, in which a comparative analysis is performed of alternative courses of action in terms of both their costs and consequences, ${ }^{6}$ on the basis of the currently available evidence.

\section{Table 1 - Alternative follow-up strategies.}

Follow-up strategy

Imaging three months after RT

\begin{tabular}{|c|c|c|c|c|}
\hline & \\
\hline & & No recurrence & $\mathrm{PD}$, treated & PD, not treated \\
\hline Usual & CXR + on basis of symptoms ${ }^{a}$ & CXR & Chest CT & None \\
\hline CT-based & Chest CT + on basis of symptoms ${ }^{a}$ & CXR & Chest CT & None \\
\hline PET-CT-based & PET-CT & CXR & Chest CT & None \\
\hline
\end{tabular}

\begin{tabular}{l}
\hline Symptoms \\
Pain \\
Localised \\
Diffuse \\
Dyspnoea \\
Cough \\
Dysphagia \\
Malaise \\
Neurological \\
Palpable mass \\
Fatigue
\end{tabular}

CXR: chest radiography; PD: progressive disease.

a Imaging on the basis of symptoms.

\section{Diagnostics}

Coventional radiography of involved region Bone scintigraphy

CXR

CXR

Chest CT

CXR + screening blood sample

CT brain

CT of involved region

Screening blood sample 
To be able to add this information to the decision-making process, we performed the current economic evaluation to evaluate the cost-effectiveness of PET-CT-based follow-up as opposed to conventional follow-up in NSCLC patients treated with curative (chemo)RT.

\section{Patients and methods}

Three follow-up strategies were compared with different imaging methods 3 months after therapy: the 'usual' or conventional follow-up (anamnesis, physical examination and a chest X-ray), the PET-CT-based follow-up (anamnesis, physical examination and a PET-CT scan) and the CT-based follow-up (anamnesis, physical examination and a chest CT scan). After the 3 months post-treatment time point, the follow-up was the same for the different strategies. Details regarding these follow-up policies are provided in Table $1 . \mathrm{Be}$ cause the results of the prospective study implied that the advantage of the PET-CT seems to be confined to the patient group without symptoms at the time of the PET-CT scan (55\% of patients), ${ }^{5}$ we additionally examined a strategy where a PET-CT was applied only in the asymptomatic subgroup. Within this strategy, symptomatic patients did not receive a standard PET-CT scan, but underwent imaging on the basis of the location of symptoms (conform Table 1).

\subsection{Model structure}

A Markov transition model was constructed with mutually exclusive health states to compare long-term costs and effects of the different follow-up strategies (Fig. 1). ${ }^{7}$

The model simulated the course of events in a hypothetical cohort of NSCLC patients treated with curative RT with or without chemotherapy. Health states in the model were based on the absence or presence of progression and on the treatment of progression. Patients without progression were in the health state 'no evidence of disease'. Patients with progression were subdivided according to their treatment: progression without treatment, progression with palliative treatment or progression with curative treatment. Patients in the CT-based or usual follow-up strategy, who had progression 3 months after treatment that was only detected with PET-CT and not with CT alone, were assigned the health state 'progression not detected'. The final health state was 'death'.

The start of the model was set after the first follow-up visit 3 months after radical therapy. At this time point, patients were divided between the different health states on the basis of the results of our prospective study. ${ }^{5}$ In the model, patients moved between health states according to a set of transition probabilities. The cycle length of the model was 6 months, with a time horizon of 5 years.

\subsection{Data sources}

Input parameters were derived from the prospective study performed at our institute, published literature, the Dutch Health Insurance Board, and, if no other source was available, expert opinion. Details of the prospective study are published elsewhere. ${ }^{5}$ In short, 100 patients with NSCLC, treated with curative intent with (chemo)radiation, were prospectively evaluated. All patients underwent a planned FDG-PET-CT scan 3 months after the start of radiotherapy, regardless of the presence of symptoms. Patients were judged symptomatic when any symptom was either new or had increased over time from the end of RT. Twenty-four percent (95\% CI: 17-33\%) of patients had progression 3 months post-treatment. No curative treatment could be offered to any of the patients who were symptomatic at the time of progression. In 2 of the 55 asymptomatic patients (4\%, 95\% CI: $1-12 \%)$, tumour progression, amenable for curative therapy, was found, which was detected with PET, not with CT only. The first patient was treated with re-irradiation for a locoregional recurrence, the 2nd patient was treated with adrenal resection for bilateral adrenal metastases.

\subsection{Probabilities}

All probabilities are listed in Table 2. As the cycle length was 6 months, probabilities of moving from one health state to another were calculated as 6 monthly transition probabilities.

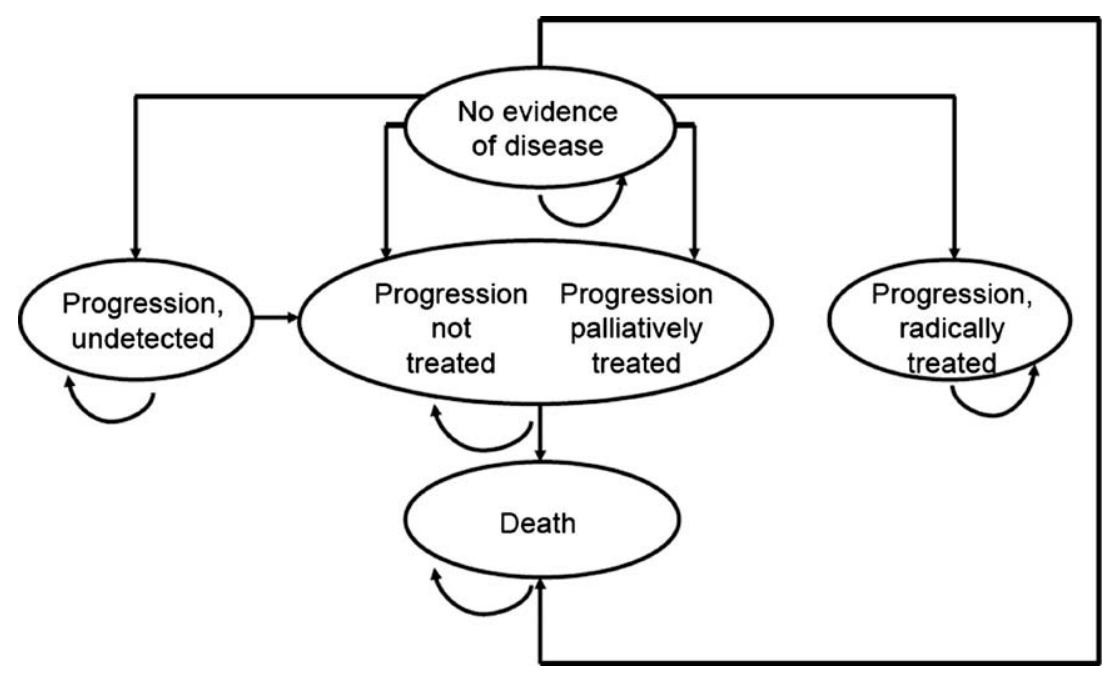

Fig. 1 - Markov model. A hypothetical cohort of patients enters the model after the follow-up visit 3 months after radical (chemo-)RT. Patients are divided over the different health states according to the results of the prospective study. 


\section{Table 2 - Inputs.}

Estimated value

Symptoms without PD

Strategy-dependent probabilities

PET-CT

Detection of symptomatic PD

Detection of asymptomatic PD

Treatment of asymptomatic PD

Treatment of symptomatic PD

Radical treatment of asymptomatic PD

Radical treatment of symptomatic PD

CT

Detection of symptomatic PD

Detection of asymptomatic PD

Treatment of asymptomatic PD

Treatment of symptomatic PD

Radical treatment of asymptomatic PD

Radical treatment of symptomatic PD

Usual

Detection of symptomatic PD

Detection of asymptomatic PD

Treatment of asymptomatic PD

Treatment of symptomatic PD

Radical treatment of asymptomatic PD

Radical treatment of symptomatic PD

\section{After 3 months}

Progression

Detection of undetected PD

PD, 1st year

$\mathrm{PD}$, 2nd year

$\mathrm{PD}$, 3rd year

$\mathrm{PD}$, 4th year

Treatment

Radical

Palliative

No treatment

Death

Death with PD, no treatment

Death with PD, palliative treatment

Death with PD, radical treatment

1st year

2nd year

3rd year

Death with undetected PD

\section{Utility scores}

No PD

$\mathrm{PD}$, not treated

$\mathrm{PD}$, palliatively treated

$P D$, radically treated

$\mathrm{PD}$, undetected

\section{Costs}

Diagnostics

First 3 months

PET-CT whole body

1364
0.24

0.68

0.38

SE

Distribution

Source
1

1

0.63

0.81

0.4

0

1

0.5

0.63

0.81

0

0

1

0

0

0.81

0

0

0.8

0.21

0.16

0.23

0.12

0.01

0.56

0.43

0.56

0.46

0.33

0.18

0.02

0.54

0.68

0.53

0.53

0.68

0.53
0.04

0.09

0.06

Fixed

Fixed

0.16

0.095

0.2

Fixed

Fixed

0.17

0.16

0.095

Fixed

Fixed

Fixed

Fixed

Fixed

0.095

Fixed

Fixed

Fixed

0.036

0.036

0.036

0.036

0.02

0.02

0.02

0.025

0.025

0.019

0.019

0.019

0.025

0.1

0.1

0.1

0.1

0.1
Beta
Beta
Beta

[5]

[5]

[5]
EO

EO

[5]

[5]

[5]

[5]

Beta

Beta

[5]

[5]

[5]

[5]

[5]

EO

EO

[5]

Beta

[5]

[5]
EO

Beta

[3]

Beta

Beta

beta

[3]

[3]

Dirichlet

Dirichlet

EO

Dirichlet

[14]

Beta

Beta

[10]

[11]

Beta

Beta

Beta

Beta

$\mathrm{EO}^{\mathrm{a}}$

Beta

Beta

Beta

Beta

Beta

EO

EO

Fixed 


\begin{tabular}{|c|c|c|c|c|}
\hline & Estimated value & SE & Distribution & Source \\
\hline Chest CT & 206 & Fixed & & [33] \\
\hline CXR & 39 & Fixed & & [33] \\
\hline Follow-up visit & 59 & Fixed & & [33] \\
\hline \multicolumn{5}{|l|}{ After 3 months ${ }^{b}$} \\
\hline \multicolumn{5}{|l|}{ Follow-up, No PD ${ }^{\mathrm{c}}$} \\
\hline 1st year & 196 & Fixed & & [33] \\
\hline 2nd year & 98 & & & \\
\hline $3 r d+$ year & 49 & & & \\
\hline \multicolumn{5}{|l|}{ Follow-up, PD } \\
\hline Treated ${ }^{\mathrm{d}}$ & 529 & Fixed & & [33] \\
\hline Untreated $^{\mathrm{e}}$ & 118 & Fixed & & [33] \\
\hline \multicolumn{5}{|l|}{ Treatment } \\
\hline Probability of 2nd line chemotherapy & 0.47 & & & {$[14]$} \\
\hline Probability of palliative RT & 0.18 & 0.018 & Beta & {$[34]$} \\
\hline \multicolumn{5}{|l|}{ Unit costs } \\
\hline Radical $^{\mathrm{f}}$ & 5746 & Fixed & & {$[5,33]$} \\
\hline \multicolumn{5}{|l|}{ Palliative chemotherapy } \\
\hline \multicolumn{5}{|l|}{ 1st line ${ }^{g}$} \\
\hline No. of cycles & 4 & & & {$[11]$} \\
\hline Costs/cycle & 1302 & & & [33] \\
\hline Side effects & 349 & & & [16] \\
\hline Total costs & 5557 & Fixed & & \\
\hline \multicolumn{5}{|l|}{ 2nd line ${ }^{\mathrm{h}}$} \\
\hline Mean treatment time (days) & 125 & & & [33] \\
\hline Costs/treatment & 9100 & & & [33] \\
\hline Side effects & 120 & & & {$[16]$} \\
\hline Total costs & 9220 & Fixed & & \\
\hline Palliative RT & 1017 & Fixed & & [33] \\
\hline \multicolumn{5}{|l|}{ Dying } \\
\hline Dying of cancer, terminal care $\mathrm{e}^{\mathrm{i}}$ & 11,602 & 800 & Gamma & {$[17]$} \\
\hline Dying of other causes & 15,448 & 800 & Gamma & [17] \\
\hline $\begin{array}{l}\text { EO: expert opinion; CXR: chest X-ray; RT: rad } \\
\text { a Calculated from the probability of dying wi } \\
\text { b Costs per } 6 \text { monthly cycle. } \\
\text { c Based on follow-up visit with CXR, } 4 \text { times } \\
\text { d Based on follow-up visit with chest-CT, } 4 \text { ti } \\
\text { e Based on follow-up visit without imaging, } \\
\text { f Based on type of radical treatment in prosf }\end{array}$ & $\begin{array}{l}\text { DHIB: Dutch Health } \\
\text { rence without treatn } \\
\text { r, } 2 \text { times in } 2 \text { nd yea } \\
\text { ar. } \\
\text { dy, being adrenal res }\end{array}$ & $\begin{array}{l}\text { Board. } \\
\text { th pallia } \\
\text { a year th }\end{array}$ & tment. & \\
\hline $\begin{array}{l}\text { g Docetaxel, 3-weekly cycles. } \\
\text { h Erlotinib. }\end{array}$ & & & & \\
\hline
\end{tabular}

The median age of patients assumed to enter the model was 62 years, based on the patient characteristics of the prospective study. ${ }^{5}$ The extra mortality risk for surviving lung cancer patients as opposed to the general population was 1.4. ${ }^{8,9}$ Agespecific mortality rates were used for 5 -year age groups (Central Bureau for Statistics, 2007). The probability of progression after 3 months was calculated on the basis of a prospective study of Mac Manus and colleagues (1-, 2-, 3- and 4-year progression free survival rates of $62 \%, 44 \%, 26 \%$ and $20 \%$, respectively). ${ }^{3}$ Patients with progression that was not treated were assumed to have a 1-year overall survival (OS) of $19 \%{ }^{10}$; patients who were palliatively treated for progression were assumed to have a 1 -year OS of $30 \%{ }^{11}$ The 1 -year OS for patients who were treated with curative intent was assumed to be $45 \%$, based on published results with re-irradiation and adrenal resection. ${ }^{12,13}$ Percentages of patients receiving 2nd and 3rd line chemotherapy were based on a retrospective chart review of 417 patients with advanced NSCLC. ${ }^{14}$

\subsection{Costs}

An overview of the costs associated with the follow-up procedures, treatment and terminal care is outlined in Table 2. All costs are reported in Euros and converted to the year 2008. Future costs and effects were discounted to their present value by a rate of $4 \%$ and $1.5 \%$, respectively. ${ }^{15}$ Costs of diagnostic procedures and treatment were derived from the Dutch Health Insurance Board, adjusted to the 2007 price level (Central Bureau for Statistics 2007). The costs for first line chemotherapy were based on 4 cycles of docetaxel $75 \mathrm{mg} / \mathrm{m}^{2}$. Costs 
Table 3 - Cost-effectiveness of different follow-up strategies.

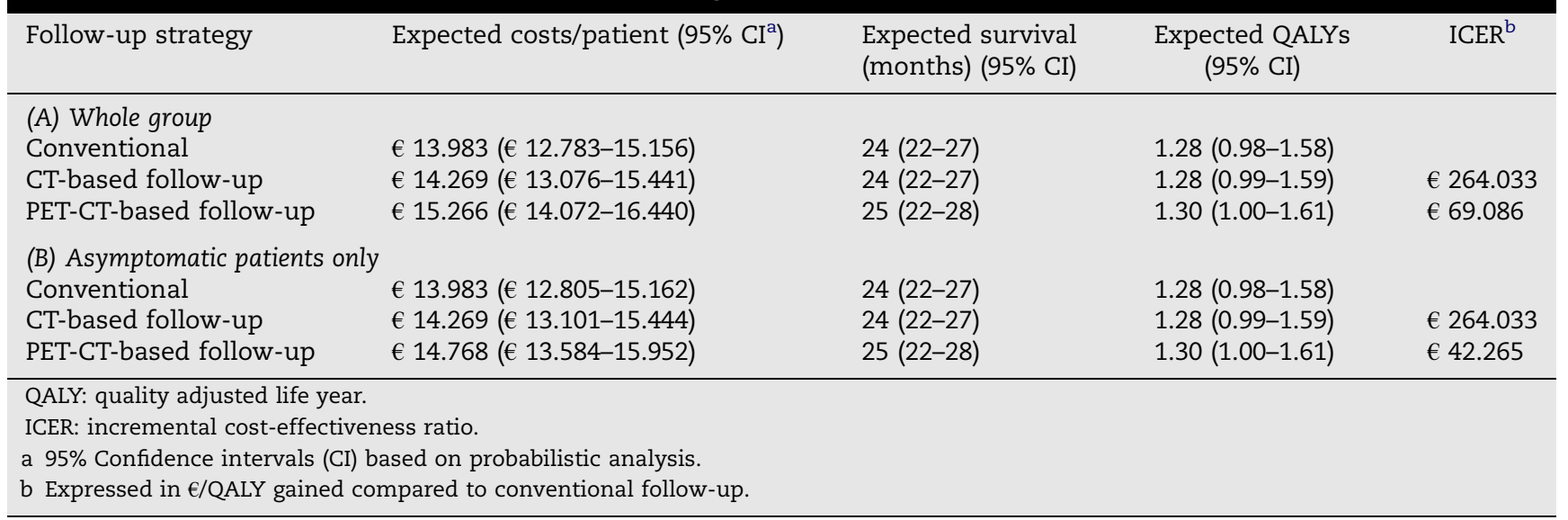

of second line chemotherapy were based on treatment with erlotinib during 125 days. Costs associated with side effects were based on calculations from the National Institute for Clinical Excellence. ${ }^{16}$ The costs associated with dying were based on a report of Kommer and Polder ${ }^{17}$ in which costs associated with cancer death are described separately from costs associated with dying from other causes.

\subsection{Effects}

Global health-related quality of life (QOL) data were expressed in utility scores, varying from zero (death) to one (perfect health). The use of utility scores allows the calculation of Quality Adjusted Life Years (QALYs) and cost per QALY ratios. Utility scores were derived from a cross-sectional study performed by Trippoli and colleagues. ${ }^{18}$ Based on this study, patients with progression had a utility score of 0.53 , while patients without progression had a utility score of 0.68 . Patients with progression that was curatively treated were assumed to have the same utility score as patients without progression, based on expert opinion (DDR). Furthermore, patients who were treated with palliative intent for PD were assumed to have the same utility as patients who received no treatment, on the basis of literature showing no significant difference in QOL with the administration of docetaxel $75 \mathrm{mg} / \mathrm{m}^{2}$ as second line chemotherapy. ${ }^{19}$ All utility scores are listed in Table 2.

\subsection{Cost-effectiveness analysis}

The analysis was performed from a health care perspective. The cost-effectiveness of the different follow-up strategies was compared using incremental cost-effectiveness ratios (ICERs), calculating the incremental costs per QALY gained. Whether a follow-up strategy is deemed cost-effective depends on how much the society is willing to pay for a gain in effect, which is referred to as the ceiling ratio. The Dutch Health Council advises an informal ceiling ratio of $€ 80.000$. $^{20}$

The input parameters of the model are inevitably associated with uncertainty. Probabilistic modelling is used to reflect this uncertainty in the parameters and to describe the effects on uncertainty over the outputs of interest. ${ }^{21}$ Distributions to the model parameters, based on their mean value and standard error, were assigned to reflect the uncertainty in the estimation of that parameter (Table 2). ${ }^{22}$ A probabilistic sensitivity analysis was performed using Monte Carlo simulation with 5000 random iterations from the assigned distributions. To illustrate the results of the simulation, cost-effectiveness acceptability curves (CEACs) were calculated to characterise the likelihood that a certain follow-up strategy would be deemed cost-effective at different ceiling ratios, ${ }^{21,23}$ representing the uncertainty surrounding the cost-effectiveness for this range of thresholds.

\subsection{Expected value of perfect information}

As uncertainty exists, there is always a chance that the 'wrong' decision will be made. ${ }^{21,24}$ In this case, society would suffer a loss as a consequence. The decision to reduce the chance of a wrong decision by performing additional research involves balancing between the costs of acquiring more information with the value associated with it. The EVPI (expected value of perfect information) is the expected value of obtaining perfect knowledge of the 'true' values of all parameters. We calculated the total EVPI by subtracting the net monetary benefit of the follow-up strategy we would choose under conditions of uncertainty, from the net monetary benefit of the optimal decision we would make if we knew the 'true' parameter values. The population EVPI was then calculated by multiplying the EVPI per patient by the number of patients who could potentially benefit from additional research. In the present study, this is the total number of patients with inoperable NSCLC treated with curative intent with (chemo)RT. We estimated that of the 1.35 million lung cancer patients per year, of whom $80 \%$ have NSCLC, $30 \%$ are amenable for curative (chemo)RT, being a total of 1.5 million patients worldwide in the next 5 years.

\section{Results}

\subsection{Cost-effectiveness of different follow-up strategies}

Results of the analysis regarding the cost-effectiveness of the different follow-up strategies are presented in Table 3A. With 

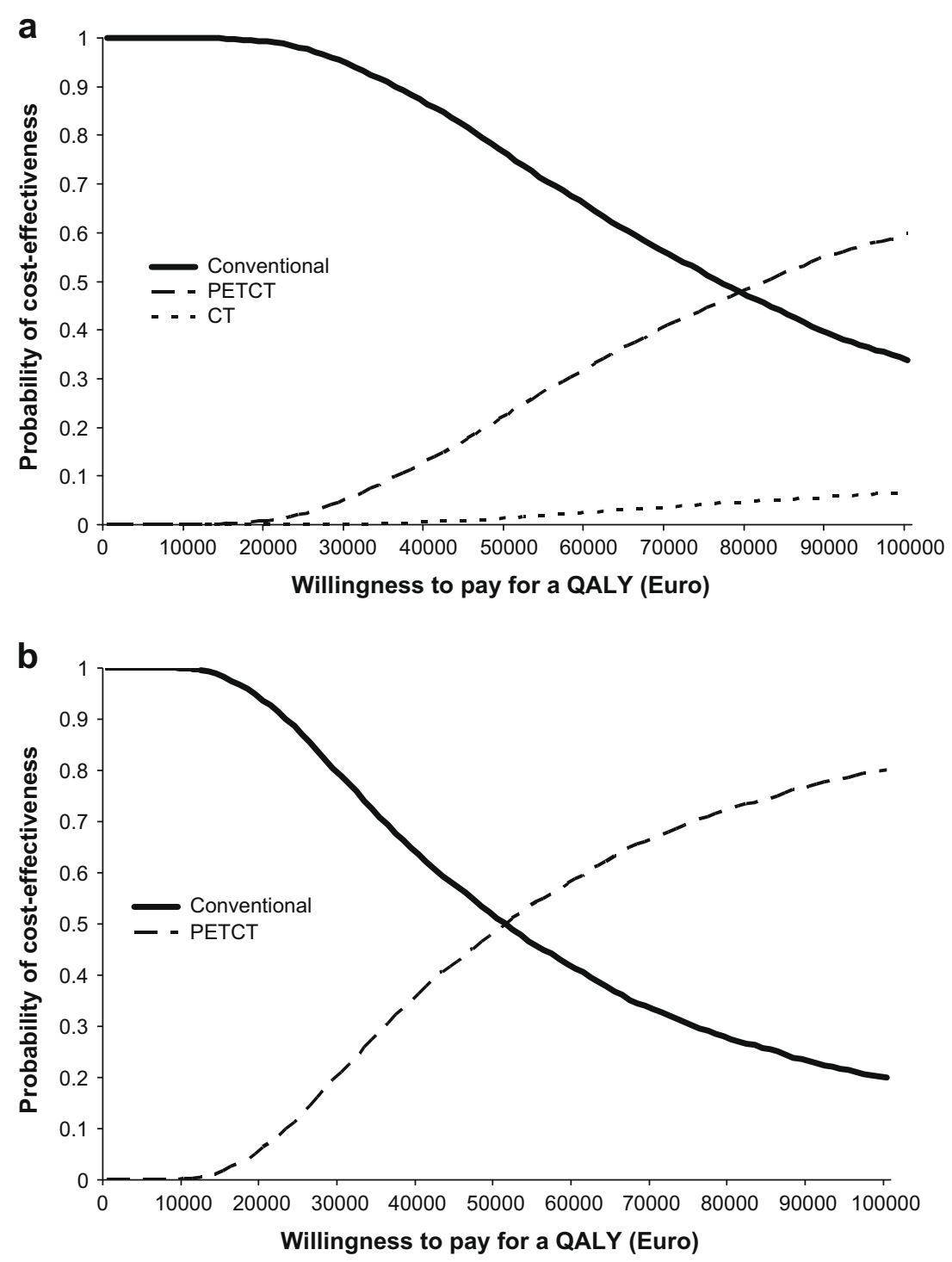

Fig. 2 - Cost-effectiveness acceptability curves (CEACs). The probability of cost-effectiveness of a certain follow-up strategy is plotted against the willingness to pay per quality adjusted life year (QALY) gained. (a) CEAC for the strategy in which a PET-CT is performed in all patients. (b) CEAC for the strategy in which a PET-CT is performed in asymptomatic patients only.

regard to PET-CT-based follow-up, the additional costs per extra curatively treated patient were $€ 64.096$ compared to conventional follow-up. The ICER (incremental cost-effectiveness ratio) for PET-CT-based follow-up was $€ 69.086$ per QALY gained compared to conventional follow-up. Although CTbased follow-up was less costly, it was also less effective than PET-CT-based follow-up, resulting in an ICER of $€ 264.033$ per QALY gained.

Fig. 2a shows cost-effectiveness acceptability curves for the 3 follow-up strategies. The figure shows that there is considerable uncertainty regarding which follow-up strategy is deemed cost-effective around the informal threshold of the Dutch Health Council. Given this ceiling ratio of $€ 80.000,{ }^{20}$ PET-CT-based follow-up and conventional follow-up had a similar probability of being cost-effective (48\% and $47 \%$, respectively), while the probability of CT-based follow-up being cost-effective was only $5 \%$ (Fig. 2 a).
3.2. Cost-effectiveness of a follow-up strategy with a PET$\mathrm{CT}$ in the asymptomatic subgroup

The same analysis was performed, but a PET-CT scan was now only performed in patients who were asymptomatic 3 months after treatment (55\% of patients) (Table 3B). Symptomatic patients received imaging on the basis of the location of symptoms. The usual follow-up strategy and CT-based follow-up strategy remained the same. Performing PET-CT-based follow-up only in the asymptomatic subgroup had no influence on the effects, but reduced the costs per patient from $€$ 15.265 to $€ 14.767$. Hence, this strategy resulted in a lower ICER of $€ 42.265$ per QALY gained as opposed to conventional follow-up. With this strategy, PET-CT-based follow-up had the highest probability of being cost-effective (73\%) compared to conventional follow-up (27\%) at a ceiling ratio of $€ 80.000$ Fig. 2b). 


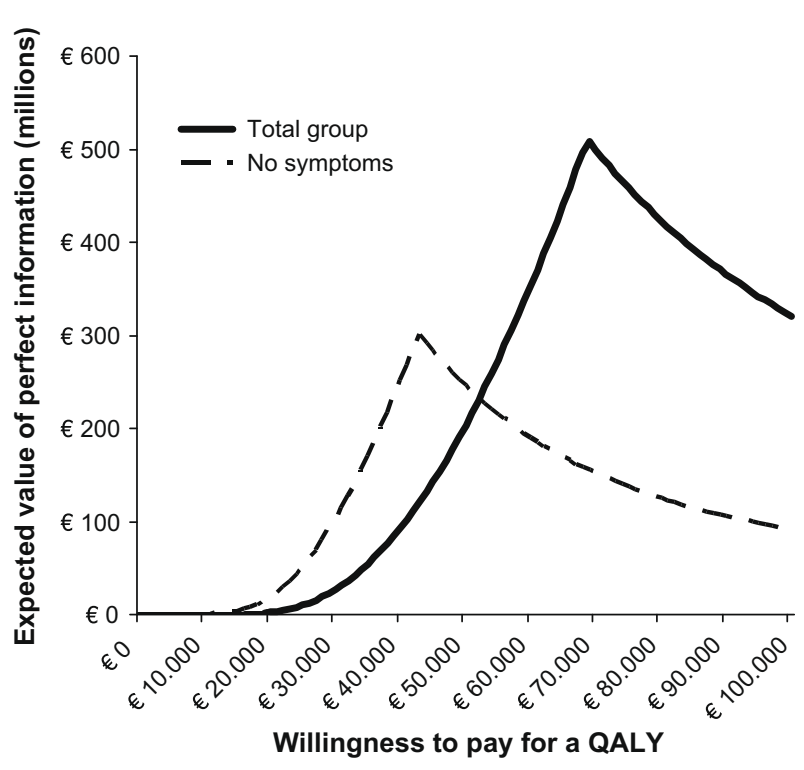

Fig. 3 - Expected value of perfect information (EVPI). The expected value of perfect information at different ceiling ratios. Total group: EVPI for the strategy in which a PET-CT is performed in all patients. No symptoms: EVPI for the strategy in which a PET-CT is performed in asymptomatic patients only.

\subsection{Expected value of perfect information}

In the current analysis, the uncertainty surrounding the decision whether or not to implement PET-CT-based follow-up resulted in an EVPI of $€ 282$ per person, given a ceiling ratio of $€$ 80.000. Implementing PET-CT-based follow-up affects all patients with locally advanced NSCLC, treated with curative (chemo)RT, involving a total of 1.5 million patients worldwide in the next 5 years. This makes the population EVPI $\left(1.5 * 10^{6}\right) * 290=€ 423$ million, meaning that perfect information on this topic is worth $€ 423$ million.

The EVPI for the implementation of PET-CT-based followup only in the subgroup of asymptomatic patients was $€ 83$ per person, given a ceiling ratio of $€ 80.000$. The population EVPI for this strategy was $€ 125$ million. The population EVPI for different ceiling ratios, both for the total group and for the asymptomatic subgroup, is presented in Fig. 3.

\section{Discussion}

Until now, no imaging procedure has become standard in the follow-up of NSCLC, mainly because of the fact that progression or recurrence is mostly detected at a stage that no curative treatment is possible, and hence, no survival benefit can be expected..$^{25}$ Our recent prospective study on a single ${ }^{18}$ FDGPET scan 3 months post-therapy confirmed the hypothesis that this imaging modality, in contrast to CT alone, is able to detect progression amenable for curative treatment in a small percentage of patients. The question remained, however, whether this potential benefit for the individual patient outweighs the increased costs. ${ }^{26}$

The current economic evaluation shows that performing a PET-CT scan 3 months after curative (chemo-)RT is a poten- tially cost-effective follow-up method, and is more cost-effective than CT alone. Performing a PET-CT scan only in the subgroup of asymptomatic patients is probably as effective and more cost-effective.

Inherently to the design of the study, there are some limitations that need to be addressed. Firstly, the current results are surrounded by considerable uncertainty, caused by uncertainty in the input parameters of the model. One important cause is the relatively small patient population $(N=100)$ in the prospective study, from which the extent of the potential benefit of PET-CT was derived. ${ }^{5}$ This economic evaluation aimed however, to base the decision regarding which follow-up strategy is to be preferred on the currently available evidence. Decisions will have to be made anyway, so it is better to support the decision with the available evidence including its uncertainties than doing something without any evidence at all. ${ }^{27}$ Using decision-analytic modelling we were able to incorporate this uncertainty in the model by assigning distributions to the model parameters. The incorporation of uncertainty also makes results easier to interpret by decision makers, as one can calculate which strategy has the highest probability of being cost-effective at different ceiling ratios (Fig. 2). The EVPI analysis shows us to what extent reduction of uncertainty by performing additional research is worthwhile. The value of totally eliminating uncertainty of the input parameters of the model was $€ 435$ million, for a ceiling ratio of $€ 80.000$, implying that additional research on this subject is of great value and outweighs the associated costs.

Secondly, the threshold (also referred to as the ceiling ratio) below which a certain strategy is considered cost-effective is arbitrary and differs between countries. In the current analysis, a threshold of $€ 80.000$ (informal ceiling ratio of the Dutch Health Council) was used. Thresholds reported in literature range from $€ 35.000$ (\$50.000) to $€ 210.000$ (\$ $300.000) .{ }^{26,28,29}$ With a higher ceiling ratio, the probability that the PET-CT-based follow-up strategy is cost-effective becomes higher, while the usual follow-up strategy has the highest probability of being cost-effective at lower ceiling ratios. Hence, whether a strategy is deemed cost-effective depends on how much the society is willing and able to pay for a gain in effect.

Thirdly, the use of a model to estimate costs and effects is always associated with a simplification of reality. ${ }^{27}$ In the current analysis, we have chosen to compare the PET-CT-based follow-up method with two follow-up strategies most commonly used according to the guidelines of the different institutions. ${ }^{1}$ Furthermore, in the model, the difference between the three strategies was based upon different imaging only at one time point during follow-up, i.e. 3 months after curative treatment. This time point was chosen based on the prospective study which showed a possible advantage of PET over CT in detecting potentially curable progression at 3 months after treatment and because a PET scan performed at this interval has shown to be prognostic of outcome. ${ }^{2,4}$ In none of the patients in the prospective study, additional investigations were requested to confirm the findings of the PET-CT scan. Hence, in the current economic evaluation, no costs were calculated to take into account false positive findings in the PET-CT strategy. No costs were calculated for false positive findings in the usual and CT-based follow-up strategy 
either, minimising the chance of overestimating the costeffectiveness of PET-CT. Another drawback of the limitation to one time point is that the potential gain of repeated imaging with e.g. chest CT scans cannot be derived from this study. The available literature however, does not confirm a benefit of repeated CT-scanning in the follow-up. ${ }^{30}$ A definitive answer regarding the value of CT-based follow-up can be expected from a multicentre phase III trial which is currently ongoing in France, in which conventional follow-up with chest X-rays is compared with an intensive follow-up strategy with repeated chest CT scans in NSCLC patients after curative resection. $^{31}$

The performed economic evaluation is aimed to guide decision making regarding which strategy to choose, and is not intended to reveal scientific truth. ${ }^{22}$ On the basis of the currently available evidence, however, the following conclusions can be drawn: Firstly, performing a chest CT scan in the follow-up is less cost-effective than performing a PET-CT scan 3 months after treatment. Hence, if any imaging is wished to be performed for treatment evaluation, one would prefer to perform a PET-CT scan 3 months after therapy above CT alone. Secondly, irrespective of the question whether certain imaging is cost-effective, the final decision to perform the test depends on what the society can afford. ${ }^{26}$ Finally, the results show that it is worthwhile to perform additional research to reduce the uncertainty surrounding the decision whether to implement PET-CT in the follow-up, including questions regarding the time point and frequency and what the additional financial burden is.

\section{Conflict of interest statement}

None declared.

\section{REFERENCES}

1. Rubins J, Unger M, Colice GL. Follow-up and surveillance of the lung cancer patient following curative intent therapy: ACCP evidence-based clinical practice guideline (2nd edition). Chest 2007;132(3 Suppl.):355S-67S.

2. Mac Manus MP, Hicks RJ, Matthews JP, et al. Positron emission tomography is superior to computed tomography scanning for response-assessment after radical radiotherapy or chemoradiotherapy in patients with non-small-cell lung cancer. J Clin Oncol 2003;21(7):1285-92.

3. Mac Manus MP, Hicks RJ, Matthews JP, et al. Metabolic (FDG$\mathrm{PET}$ ) response after radical radiotherapy/chemoradiotherapy for non-small cell lung cancer correlates with patterns of failure. Lung cancer 2005;49(1):95-108.

4. Patz Jr EF, Connolly J, Herndon J. Prognostic value of thoracic FDG PET imaging after treatment for non-small cell lung cancer. AJR Am J Roentgenol 2000;174(3):769-74.

5. van Loon J, Grutters J, Wanders R, Boersma L, Oellers M, Dingemans AM, et al. Follow-up with 18FDG-PET-CT after radical radiotherapy with or without chemotherapy allows the detection of potentially curable progressive disease in non-small cell lung cancer patients: a prospective study. Eur $J$ Cancer 2009;45(4):588-95.
6. Drummond MF, Sculpher MJ, Torrance GW, O'brien B, Stoddart GL. Methods for economic evaluation of health care programmes. Oxford: Oxford University Press; 2005.

7. Sonnenberg FA, Beck JR. Markov models in medical decision making: a practical guide. Med Decis Making 1993;13(4): 322-38.

8. Sugimura H, Yang P. Long-term survivorship in lung cancer: a review. Chest 2006;129(4):1088-97.

9. Wingo PA, Ries LA, Parker SL, Heath Jr CW. Long-term cancer patient survival in the United States. Cancer Epidemiol Biomarkers Prev 1998;7(4):271-82.

10. Shepherd FA, Dancey J, Ramlau R, et al. Prospective randomized trial of docetaxel versus best supportive care in patients with non-small-cell lung cancer previously treated with platinum-based chemotherapy. J Clin Oncol 2000;18(10):2095-103.

11. Hanna N, Shepherd FA, Fossella FV, et al. Randomized phase III trial of pemetrexed versus docetaxel in patients with nonsmall-cell lung cancer previously treated with chemotherapy. J Clin Oncol 2004;22(9):1589-97.

12. Okamoto Y, Murakami M, Yoden E, et al. Reirradiation for locally recurrent lung cancer previously treated with radiation therapy. Int $J$ Radiat Oncol Biol Phys 2002;52(2):390-6.

13. Tanvetyanon T, Robinson LA, Schell MJ, et al. Outcomes of adrenalectomy for isolated synchronous versus metachronous adrenal metastases in non-small-cell lung cancer: a systematic review and pooled analysis. J Clin Oncol 2008;26(7):1142-7.

14. Murillo Jr JR, Koeller J. Chemotherapy given near the end of life by community oncologists for advanced non-small cell lung cancer. Oncologist 2006;11(10):1095-9.

15. Guidelines for pharmaco-economic research. Diemen: Health Care Insurance Board; 2006.

16. NHS. Nice guideline costing statement: erlotinib for the treatment of NSCLC. National Institute for Clinical Excellence; 2008.

17. Kommer GSL, Polder J. Risicosolidariteit en Zorgkosten. Zoetermeer: Raad voor de Volksgezondheid en Zorg; 2005.

18. Trippoli S, Vaiani M, Lucioni C, Messori A. Quality of life and utility in patients with non-small cell lung cancer. Quality-oflife Study Group of the Master 2 Project in pharmacoeconomics. Pharmacoeconomics 2001;19(8):855-63.

19. Dancey J, Shepherd FA, Gralla RJ, Kim YS. Quality of life assessment of second-line docetaxel versus best supportive care in patients with non-small-cell lung cancer previously treated with platinum-based chemotherapy: results of a prospective, randomized phase III trial. Lung cancer 2004;43(2):183-94.

20. Sensible and sustainable care (in Dutch). Zoetermeer; 2006.

21. Briggs ACK, Sculpher M. Decision modelling for health economic evaluation. Oxford University Press; 2006.

22. Weinstein MC. Recent developments in decision-analytic modelling for economic evaluation. Pharmacoeconomics 2006;24(11):1043-53.

23. Fenwick E, Claxton K, Sculpher M. Representing uncertainty: the role of cost-effectiveness acceptability curves. Health Econ 2001;10(8):779-87.

24. Claxton K, Sculpher M, Drummond M. A rational framework for decision making by the National Institute for Clinical Excellence (NICE). Lancet 2002;360(9334):711-5.

25. Edelman MJ, Meyers FJ, Siegel D. The utility of follow-up testing after curative cancer therapy. A critical review and economic analysis. J Gen Intern Med 1997;12(5):318-31.

26. Shih YC, Halpern MT. Economic evaluations of medical care interventions for cancer patients: how, why, and what does it mean? CA Cancer J Clin 2008;58(4):231-44. 
27. Grutters JP, Joore MA, van der Horst F, Stokroos RJ, Anteunis LJ. Decision-analytic modeling to assist decision making in organizational innovation: The case of shared care in hearing aid provision. Health Serv Res 2008.

28. Ubel PA, Hirth RA, Chernew ME, Fendrick AM. What is the price of life and why doesn't it increase at the rate of inflation? Arch Intern Med 2003;163(14):1637-41.

29. Buxton MJ. Economic evaluation and decision making in the UK. Pharmacoeconomics 2006;24(11):1133-42.

30. Benamore R, Shepherd FA, Leighl N, et al. Does intensive follow-up alter outcome in patients with advanced lung cancer? J Thorac Oncol 2007;2(4):273-81.

31. Westeel V, Lebitasy MP, Mercier M, et al. IFCT-0302 trial: randomised study comparing two follow-up schedules in completely resected non-small cell lung cancer. Rev Mal Respir 2007;24(5):645-52.

32. Khan AJ et al. Long term disease-free survival resulting from combined modality management of patients presenting with oligometastatic, non-small cell lung carcinoma (NSCLC). Radiother Oncol 2006;81(2):163-7.

33. Oostenbrink JBC, Koopmanschap M, Rutten F. In: C.v. Zorgverzekeringen, editor. Handleiding voor kostenonderzoek, methoden en standaard kostprijzen voor economische evaluaties in de gezondheidszorg, 2004.

34. Tyldesley $\mathrm{S}$ et al. Estimating the need for radiotherapy for lung cancer: an evidence-based, epidemiologic approach. Int $J$ Radiat Oncol Biol Phys 2001;49(4):973-85. 